Itinerarios culturales y rutas turístico-culturales 03

\title{
Los itinerarios culturales en Internet
}

Mạ Luisa Bellido Gant. Profesora titular de Historia del Arte. Universidad de Granada

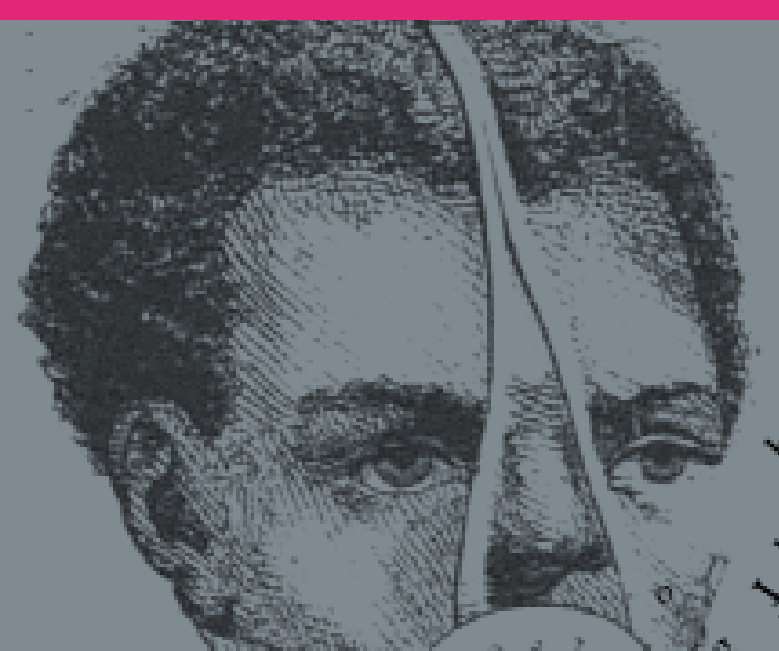


En los últimos años estamos asistiendo a la aparición de importantes cambios en el consumo turístico que están favoreciendo el surgimiento de nuevos productos siendo el turismo cultural una de las principales novedades. Dentro de este panorama los itinerarios culturales se están convirtiendo en nuevos instrumentos de atracción turística-cultural y pueden ser un factor de formación y conocimiento de la cultura propia y ajena, pero evitando valorar los monumentos y obras pictóricas de forma aislada, y procurando relacionarlos y encuadrados en un contexto lo más amplio posible. Para ello es necesario que los itinerarios se conecten con otros ámbitos más abarcables que el estrictamente local y aporten información complementaria de interés.

Uno de los atractivos del itinerario cultural es la conjunción de diversas disciplinas de la conservación del patrimonio, como la arqueología, los paisajes culturales, las ciudades históricas, la arquitectura popular, los materiales constructivos, la artesanía, la gastronomía, el folklore y las cuestiones jurídicas.

La contribución de los soportes magneto-ópticos a la difusión del conocimiento artístico y divulgación del Patrimonio Histórico ha sido especialmente importante en los últimos años; sin embargo, el coste de las producciones multimedia y el reducido mercado han hecho que las instituciones dirijan sus esfuerzos hacia la implementación de

Q Folleto 2006 de la "Ruta del Esclavo", consultable en la sección Cultura de la página web de Unesco: portal.unesco.org/culture dicha información en Internet, a través de servidores propios 0 creando un espacio corporativo en nodos gestionados por empresas de telecomunicaciones.

La aparición de Internet ha supuesto un fenómeno cultural sin precedentes que posibilita la difusión de imágenes y contenidos artísticos de todo tipo. La potencialidad de este medio es evidente y su uso así lo demuestra. Internet es ante todo un fenómeno sociológico que debemos entroncar dentro de la era de la comunicación que marca la sociedad en la que vivimos.

Es sin duda la población escolar uno de los grupos sociales que más acapara la función educativa y se ha convertido en algo habitual la visita al patrimonio por parte de escolares con la finalidad de conocer la herencia cultural de un país. La red permite visualizar prácticamente los contenidos teóricos recibidos en clase y, a partir de esta experiencia, desarrollar sus capacidades analíticas, imaginativas y creativas. Las visitas físicas suelen ir precedidas por un primer contacto entre el profesor y la institución para conocer los objetivos de la visita, el nivel de conocimiento de los alumnos, sus motivaciones, edad, intereses... La red puede facilitar al profesor información detallada y específica, el material y el equipo que está disponible y recomendaciones sobre la organización de la visita. Una ventaja fundamental es la posibilidad de proporcionar una gran cantidad de información de todo tipo (textual, gráfica, sonora) que facilita una primera aproximación al bien estudiado. La utilización de estas nuevas tecnologías aporta una serie de ventajas importantes.

En primer lugar se facilita el acceso, al permitir a cualquier visitante que viva fuera del entorno geográfico visitar el itinerario sin tener problemas de acceso y hora, ofreciendo además la posibili- 


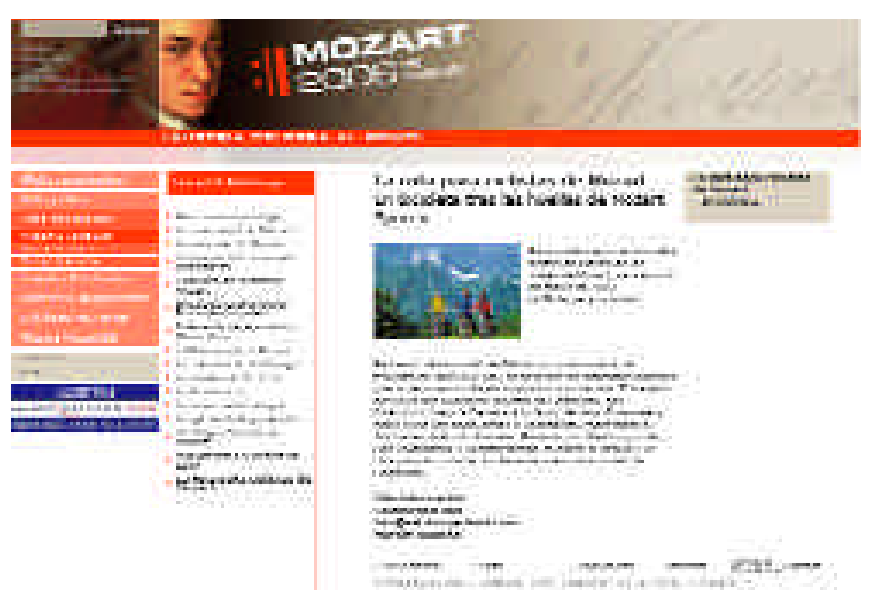

W Información en la web www.mozart2006.net sobre la "Ruta para ciclistas de Mozart", dentro del proyecto "Los caminos de Mozart en Europa"
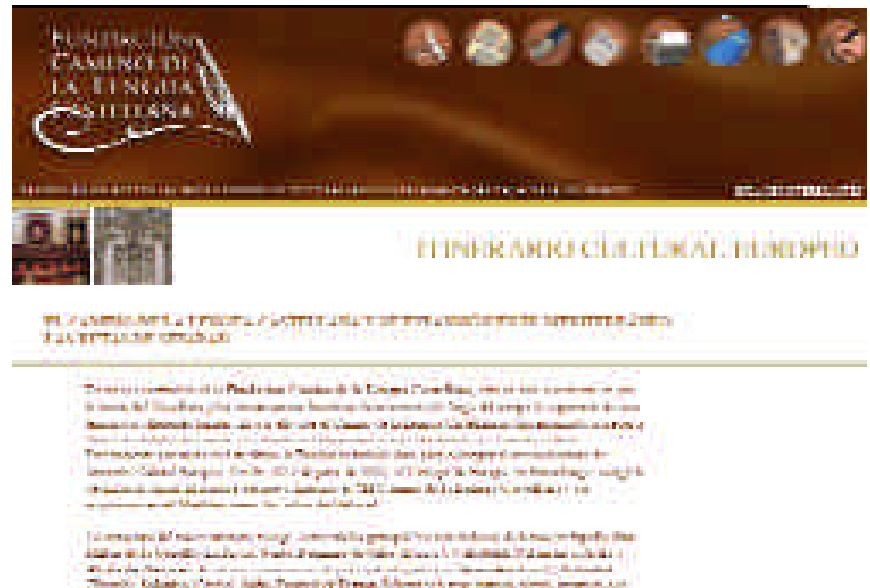

W Web del Camino de la Lengua Castellana, declarado Itinerario Cultural Europeo en 2002 (www.caminodelalengua.com)

\section{Las tecnologías favorecen la creación de rutas-imagen, supuestos itinerarios sin ninguna correspondencia física en la realidad}

dad de consultar las obras y bienes que lo conforman. También ofrece diferentes interpretaciones de las colecciones y bienes desde distintos puntos de vista, lo que redunda en una información más completa y contextualizada. Existen itinerarios virtuales que nos explican, con gran interactividad, obra por obra, siendo verdaderas experiencias formativas. Además logran organizar de una forma mucho más global y unificada las colecciones o conceptos que quieren explicarse, por ejemplo todas las obras del modernismo que están distribuidas por el mundo y que se pueden visitar virtualmente de forma conjunta en un itinerario. Incluso se pueden incluir y estudiar piezas que se encuentran desaparecidas o en colecciones privadas. En el caso de los itinerarios de arte contemporáneo, todavía muy poco desarrollados, las tecnologías multimedia combinan distintos materiales, ornatos y técnicas mezclados con sonido, imagen y movimiento.

Pero, por supuesto, no es sólo el sector escolar el que puede beneficiarse de estas posibilidades didácticas. Un buen diseño de itinerario cultural en la red abre nuevas posibilidades de comprensión de acontecimientos históricos y culturales ocurridos, nos pone en contacto con otras realidades semejantes y nos permite comparar nuestra identidad con otras. Además, la posibilidad técnica de facilitar gran información (bibliográfica, fuentes documentales, archivos gráficos y sonoros, mapas) redunda en un conocimiento más plural, interdisciplinario y contextualizador; factores, todos claves, de la nueva visión que el patrimonio quiere aportar a la sociedad contemporánea, en muchos casos demasiado cerrada a sus peculiaridades locales, perdiendo de vista la pluralidad que brinda la posibilidad de una comprensión más amplia. 


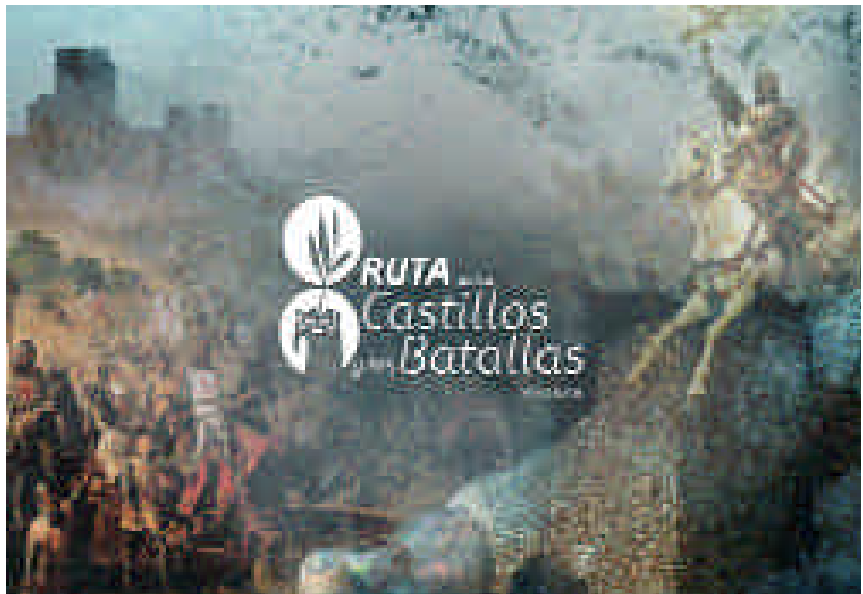

W Entrada de la Ruta de los Castillos y Batallas en www.castillosybatallas.com

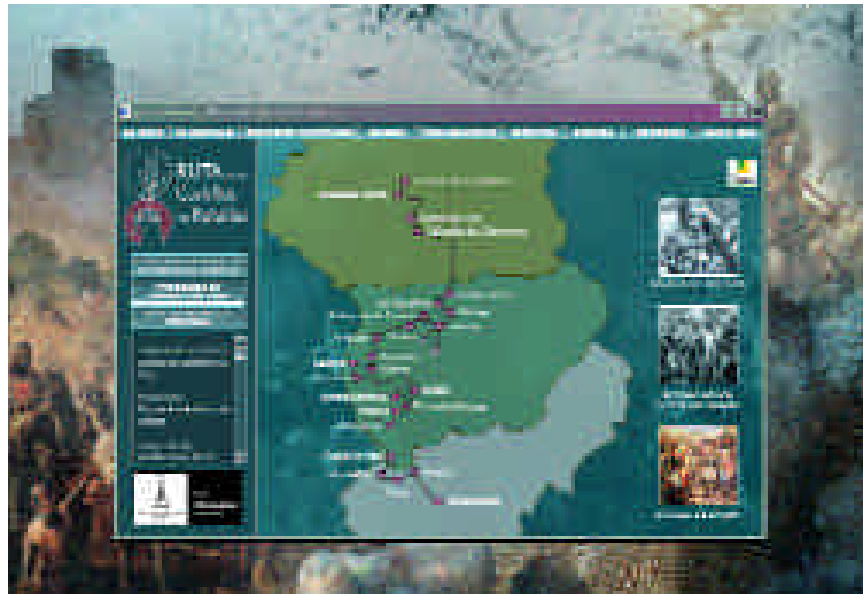

W Detalle del mapa de itinerarios de la Ruta de los Castillos y Batallas
Las ventajas y abaratamiento de estas tecnologías también conllevan un aspecto negativo, y es la existencia de supuestos itinerarios que no dejan de ser folletos más o menos elaborados e introducidos en Internet y que no se corresponden físicamente con ningún itinerario. Se trataría de rutas-imagen, donde no se realizan acciones de puesta en valor, de mejora u organización de la oferta, en muchas ocasiones ni una mínima señalización. Esta abundancia puede generar saturación en el mercado y provocar confusión en el público, además de una cierta desconfianza ante la diversidad de calidades que se ofrecen.

Sin embargo, está comprobado que un mayor conocimiento del bien aumentará las ansias por conocerlo físicamente, por lo que una mayor fluidez de la inf ormación redundará positivamente sobre la evolución de estos itinerarios y facilitará las posibilidades de difusión y educación que estas tecnologías potencian.

La presencia de los itinerarios culturales en Internet nos ofrece un panorama muy diverso y caracterizado por la dispersión y la variedad. Ésta queda reflejada en la enorme disparidad temática de los mismos, desde gastronómicos (la ruta de la miel, vino o la caña de azúcar) pasando por itinerarios de personajes (ruta de Valle-Inclán, Rosalía de Castro, Gaudí, Federico García Lorca, Quijote), tipológicos (la ruta de los monasterios, de los castillos, de las juderías o de las catedrales), hasta artísticos (la ruta del modernismo, del mudéjar o del románico).

Esta diversidad también se refleja en sus promotores, por lo general diputaciones provinciales, ayuntamientos, gobiernos autonómicos, universidades, fundaciones públicas, empresas y particulares. Esto incide en la irregular calidad: por regla general los promovidos por instituciones públicas tienen una mayor calidad y un aspecto más cuidado que los dependientes de particulares.

Un problema añadido es la existencia de distintas direcciones, realizadas por promotores distintos, de un mismo itinerario, lo que crea saturación pero también incertidumbre al usuario. Otra característica detectada es la poca utilización de las ventajas técnicas que Internet ofrece. Por ejemplo, son escasos los enlaces hipertextuales que encontramos en las páginas, limitándose en muchos casos a volcar en este soporte folletos turísticos con información insuficiente y una presentación muy pobre. Estos enlaces permitirán conectar varios itinerarios entre sí y ofrecer una información más exhaustiva.

Tampoco son muy frecuentes los mapas sensibles que aportan interactividad a la presentación y, en numerosas ocasiones, las imágenes digitalizadas no tienen la suficiente calidad. Otra carencia es la ausencia de música en estas páginas, ot ra posibilidad técnica que redundaría en una mayor difusión del patrimonio musical y que podría contextualizar mejor el contenido del itinerario.

La escasa presencia de los itinerarios en Internet queda reflejada en la carencia de enlaces directos dentro de los buscadores, enlaces que sí encontramos para museos, arqueología, patrimonio, etc.

Este panorama no debe desalentarnos; al contrario, nos encontramos ante el reto de potenciar estos productos turísticos y culturales utilizando para ello estas tecnologías que redundarán en una mayor difusión, acercamiento y disfrute de nuestro patrimonio. 